\title{
Folguedos no Rio Grande do Sul: estudos iniciais sobre folclore de margem
}

\author{
BELIZA GONZALES ROCHA \\ SABRINA MARQUES MANZKE \\ THIAGO SILVA DE AMORIM JESUS
}

\section{Resumo}

Este trabalho visa socializar resultados iniciais do Projeto de Pesquisa Projeto de Pesquisa Folguedos e Danças Folclóricas Marginais do e no Rio Grande do Sul (UFPel). Esse projeto se propõe a mapear, registrar e difundir as expressões folclóricas contidas nas manifestações encontradas e que estão à margem da cultura dominante, partindo de alinhamento teórico referenciado em trabalhos sobre danças e folclore do RS e sobre a dualidade margem-centro. $\mathrm{O}$ trabalho realizou o mapeamento inicial identificando 22 manifestações entre folguedos, danças e festas. No momento, o estudo encontrase em fase de aprofundamento da pesquisa teórica articulada com uma preparação de cunho metodológico-etnográfico para a realização da pesquisa de campo.

Palavras-chave:

Folclore de margem, manifestações populares, folguedos 


\title{
Frolics in Rio Grande do Sul: initial studies about alternative folklore
}

\author{
BELIZA GONZALES ROCHA \\ SABRINA MARQUES MANZKE \\ THIAGO SILVA DE AMORIM JESUS
}

\section{Abstract}

This work aims to socialize the initial results of the Folguedos and Folkloric Dances Project in Rio Grande do Sul (UFPel). This project proposes to map, register and disseminate the folk expressions contained in the manifestations found and that are on the margin of the dominant culture, starting from the theoretical approach referenced in works on dances and folklore of the RS and on the duality of the margin-center. The work carried out the initial mapping identifying 22 manifestations between frolics, dances and parties. At present, the study is in the process of deepening the theoretical research articulated with a methodological-ethnographic preparation for the accomplishment of the field research. 


\title{
Diversiones en el estado de Río Grande del Sur (RS - Brasil): estudios iniciales sobre el "folclore de margen"
}

\author{
BELIZA GONZALES ROCHA \\ SABRINA MARQUES MANZKE \\ THIAGO SILVA DE AMORIM JESUS
}

\section{Resumen}

Este trabajo pretende socializar resultados iniciales deProyecto del Investigación Folguedos y Danzas Folclóricas Marginales del y en Rio Grande do Sul (UFPel). El proyecto se propone mapear, registrar y difundir las expresiones folclóricas contenidas en manifestaciones encontradas que están al margen de la cultura dominante, partiendo de bases teóricas y referencias sobre danzas y folclore del RS y de la dualidad margen-centro. El trabajo realizado mapeó e identificó inicialmente $\mathbf{2 2}$ manifestaciones entre diversiones, bailes y fiestas. En este momento, el estudio se encuentra en una fase de profundización de la investigación teórica articulada con una preparación de cuño metodológicoetnográfico para la realización de la investigación de campo.

Palabras clave: Folklore de margen, manifestaciones populares, diversiones 


\section{Introdução}

O presente trabalho visa socializar resultados iniciais de pesquisa vinculada ao projeto "Folguedos e Danças Folclóricas Marginais do e no Rio Grande do Sul" ${ }^{\text {, }}$ que integra o Grupo de Pesquisa OMEGA - Observatório de Memória, Educação, Gesto e Arte (CNPq) do Centro de Artes da Universidade Federal de Pelotas-RS. O referido projeto de pesquisa pretende, através da investigação científica e de campo, mapear, registrar a difundir as expressões folclóricas contidas nas manifestações encontradas no Estado do Rio Grande do Sul. Ou seja, danças e folguedos que se distanciam da cultura dominante, porém constituem-se em espaços/coletivos e linguagens folclóricas representantes da cultura popular do Estado.

Desta forma, é válido refletir sobre as manifestações da cultura no âmbito do folclore. A respeito do conceito de folclore, a Carta Nacional de Folclore, escrita em 1951, e relida em 1995, traz:

Folclore é o conjunto das criações culturais de uma comunidade, baseado nas suas tradições expressas individual ou coletivamente, representativo de sua identidade social. Constituem-se fatores de identificação da manifestação folclórica: aceitação coletiva, tradicionalidade, dinamicidade, funcionalidade. Ressaltamos que entendemos folclore e cultura popular como equivalentes, em sintonia com o que preconiza a UNESCO. A expressão cultura popular manter-se-á no singular, embora entendendo-se que existem tantas culturas quantos sejam os grupos que as produzem em contextos naturais e econômicos específicos. Ainda, segundo a Carta: Os estudos de folclore, como integrantes das Ciências Humanas 
e Sociais, devem ser realizados de acordo com metodologias próprias dessas Ciências. Sendo parte integrante da cultura nacional, as manifestações do folclore são equiparadas às demais formas de expressão cultural, bem como seus estudos aos demais ramos das Humanidades. Consequentemente, deve ter o mesmo acesso, de pleno direito, aos incentivos públicos e privados concedidos à cultura em geral e às atividades científicas. (COMISSÃO NACIONAL DE FOLCLORE, [1951] 1995).

Diante deste panorama de resgate de expressões folclóricas, é necessário definir o que se compreende como margem, para que possamos direcionar a busca por manifestações de folguedos e danças que se distanciam do que é considerado como representação do Estado e que, portanto, não difundidas através dos meios de comunicação dominantes. Segundo Angela Prysthon (2003, p. 47) "a dualidade margem-centro sempre foi um dos principais componentes da identidade periférica” e "a cultura periférica emerge no contemporâneo como instrumento principal da desestabilização do centro”.

Esta perspectiva permite a criação do que Homi Bhabha denomina como "entre-lugar" (BHABHA, 1998), à medida que periferia e centro se mesclam e se contaminam de maneira híbrida, "um espaço-tempo em essência periférico" (PRYSTHON, 2003, p. 47). Porém, antes deste entre-lugar se estabelecer, discute-se a relação de que tudo que é considerado margem acaba por assumir uma posição não prioritária, buscando sua identidade dentro deste ambiente periférico. A perspectiva adotada por este trabalho, após as reflexões feitas, alia a ideia de margem ao conceito de potência, através da visão de Aristóteles (1977), de modo a considerá-la como um lugar onde é possível se criar algo, uma vez que por constituir-se enquanto ambiente em movimento, caracteriza-se como dinâmico e possibilita acontecimentos.

Segundo preconiza Aristóteles (1977, p. 24-25): "umas potências são postas em nós pela natureza, como os sentidos; outras nos vem como um hábito contraído, como a habilidade de tocar flauta; e outras são fruto do estudo; por exemplo, as artes”. Assim, o pensador resume: "potente é aquele que pode algo em qualquer circunstância, e de qualquer maneira [...]" (1977, p. 24-25).

A partir destas reflexões acerca da noção de margem, o projeto buscou definir qual seria a perspectiva do termo "marginal" a ser entendida e empregada na pesquisa sobre 
manifestações folclóricas no Estado. Apoiamo-nos, então, na ideia de que as manifestações que buscamos resgatar estão para além do que é definido por cultura gaúcha ${ }^{2}$ e do que se encontra neste ambiente. Contudo, apoiando-se no pensamento de Aristóteles (1977), e compreendendo a margem como um lugar que existe enquanto possibilidade, percebemos que ao valorizar e dar visibilidade a tais manifestações auxiliamos para que esta margem se estabeleça como lugar de potência.

Relacionando estas concepções com o nosso objeto de pesquisa, entendemos por "centro" as manifestações vistas como representantes protagonistas da cultura do Estado, generalizadas e visibilizadas como sendo "cultura gaúcha". E a margem, então, é entendida como o conjunto de tudo o que se encontra para além das manifestações mais difundidas ou divulgadas e que corporifica os folguedos e danças folclóricas oriundas de determinadas regiões do Estado, de certa forma, excluídas. "O lugar do periférico na configuração da cultura e na crítica, análise e teoria dessa cultura, portanto, está muito diferenciado em contraste com as disciplinas mais tradicionais" (PRYSTHON, 2003, p. 44).

\section{Movimentos iniciais}

O Projeto de PesquisaFolguedos e Danças Folclóricas Marginais do e no Rio Grande do Sul, iniciado no ano de 2014 dentro do Grupo de Estudos em Folclore, Projeto de Ensino da Universidade Federal de Pelotas. Vinculado ao Centro de Artes e ao Curso de Dança, resulta de um movimento que procura investigar e registrar as diversas manifestações populares danças folclóricas, folguedos e festas - que constituem a cultura sul-rio-grandense e possuem menor visibilidade e exposição midiática. Desde a sua formação, o projeto dialoga com diferentes áreas e cursos dentro da Universidade UFPel, tais como História, Antropologia, Música, Educação do Campo etc.

As suas primeiras ações acontecem a partir da reflexão teórico-conceitual na busca de significados para os termos norteadores iniciais da pesquisa: marginal, margem-centro, potência, hegemônico e não hegemônico. Ainda foram realizadas discussões em torno do que constituem a cultura gaúcha e a figura identitária do gaúcho. Partindo de encontros semanais, o projeto desenvolveu produções textuais geradas a partir das reflexões teórico-conceituais, realizou encontros com pesquisadores, historiadores, artistas e outros convida- 
dos que também puderam contribuir a respeito destes conceitos e relatar informações a respeito de algumas das manifestações folclóricas existentes no Estado.

Passada esta primeira etapa, o projeto realizou um diagnóstico de coletivos culturais marginais do RS, em especial as comunidades litorâneas, quilombolas e indígenas, além de outros ambientes também representativos de produções folclóricas em danças e folguedos. Para tanto, fez-se inicialmente um alinhamento teórico para dar base à pesquisa, utilizando autores que tratam sobre as manifestações encontradas no Estado. Para além disto, buscamos discutir as questões sobre cultura gaúcha, o idealismo da figura do gaúcho e o modo como o Estado se posiciona em relação à sua cultura e à cultura do restante do país, apoiados pelos pensamentos de Golin (1983) e Oliven (2006).

O que temos identificado, no caso do Rio Grande do Sul, é que o que se entende como cultura gaúcha não compreende/abrange/representa a população sul-rio-grandense, de um modo geral. A cultura dominante do Estado, que legitima e representa boa parte de seu povo e que é difundida não só nacionalmente, mas internacionalmente, tem deixado de lado grande parte do que é produzido culturalmente por diversos coletivos culturais do RS. Sendo assim, o projeto está orientado por uma necessidade de investigação e registro de danças e folguedos que se encontram à margem da cultura dominante e excluídos dos processos de comunicação midiáticos de maior abrangência no Rio Grande do Sul.

O projeto tem como ponto de partida a pesquisa e identificação das diversas manifestações populares presentes no Rio Grande do Sul que se encontram à margem do que comumente é visto e predomina como cultura gaúcha. Para tanto, buscamos distinguir o que são a cultura gaúcha e a cultura sul-rio-grandense, suas relações e diferenças, e ainda, vamos além, investigando a figura do gaúcho e os mitos criados em torno deste ícone cultural para auxiliar na compreensão contextual inerente à cultura do Estado.

A cultura gaúcha, neste sentido, se forma a partir da idealização de certos traços e atributos que juntos constituem a figura identitária do gaúcho, homem valente que se personifica no imaginário de parte dos habitantes de nosso Estado.

O modelo que é construído quando se fala em tradições gaúchas - qualquer que seja a perspectiva de quem as cultua está sempre calcado no campo, mais especificamente na re- 
gião da Campanha (localizada no sudoeste do Rio Grande do Sul e fazendo fronteira com a Argentina e o Uruguai) e na figura do gaúcho, homem livre e errante que vagueia soberano sobre seu cavalo, tendo como interlocutor privilegiado a natureza, como ela se descortina nas vastas planícies dessa área pastoril do estado. (OLIVEN, 2006, p. 97)

Quanto aos aspectos ideológicos instaurados em toda a produção cultural, e que, no caso em questão, podem referir-se ao "mito do gaúcho", Jacks (2003, p. 20-21), citando alguns estudos, diz que eles foram construídos desde muito tempo pela literatura e pelas historiografias oficiais:

uma das características básicas é o enaltecimento de um passado guerreiro, onde o historiador busca nas lutas fronteiriças com os castelhanos vitórias grandiosas, lances de heroísmo e, dominando o cenário de pampa, 'verdadeiro campo de batalha', encontra-se a figura altaneira, viril e destemida do gaúcho, 'centauro dos pampas', 'monarca das coxilhas'.

A partir destes pressupostos, a origem do povo gaúcho está ligada ao campo, à vida campeira - laçar, domar e marcar potro, conduzir tropa e sair para a faina diária quebrando a geada nas madrugadas de inverno. A virilidade passou a ser a qualidade mais exigida e apreciada do gaúcho, porém, em algumas regiões do estado os grandes estancieiros da época não descuidaram da educação de seus filhos homens, que, na maioria das vezes, eram mandados para a Europa para estudar. Aqueles que não saíam do país estudavam no Rio de Janeiro, na época ainda capital do Brasil. Estes voltavam formados, cultos, alguns doutores, mas na volta o seu lugar já estava definido pelo pai: a frente dos seus negócios na estância, que podia ser de criação de animais, charqueadas, ambas e entre outras.

A figura do gaúcho, alimentada e enriquecida pela legenda, ia projetar-se no tempo e ganhar espaço, já agora liberta de seus caracteres primitivos, e acabaria como uma espécie de mimetismo sociológico, absorvendo na sua estrutura moral todos os rio-grandenses identificados com a terra não só por filiação histórica, mas ainda por aculturação ou adesão afetiva (GLOBO, 1969, p. 62).

Para Tau Golin (1983), a ideologia da cultura gaúcha persiste em seguir ideias de um tempo passado que foram modifi- 
cadas historicamente para habitar um imaginário que pertence a outro contexto social e histórico. Tal ideologia apoia-se no tradicionalismo ${ }^{3}$, movimento dotado de regras, que cultua a cultura gaúcha, glorificando os feitos do passado e buscando preservar, vivenciar e difundir esta imagem dentro e fora do Rio Grande do Sul.

Por outro lado, defendemos que a cultura sul-rio-grandense não é sinônimo de cultura gaúcha. A primeira procura abarcar (e abarca num processo quase natural e violento) tudo o que representa o Estado desde a sua formação, considerando todas as suas questões históricas e culturais, as influências vindas da colonização e também dos países fronteiriços. A cultura sul-rio-grandense possibilita que se veja a construção cultural do Estado de forma mais ampla, deixando vir à tona as expressões multiculturais contidas em cada canto do RS, e a partir disso criando uma identidade diversa, abrangente, plural e anônima que represente os seus habitantes, e não somente uma parte deles. A partir daí o enaltecimento apenas do gaúcho, "centauro dos pampas", abre espaço para o enaltecimento de antepassados como negros, indígenas e tantas outras etnias que constituíram o Rio Grande do Sul.

Tendo em vista estas discussões, o projeto tem a intenção de contribuir para a produção de conhecimento acadêmico a respeito das expressões folclóricas do RS (folguedos e danças), de modo a ampliar a compreensão acerca do universo abrangido, extrapolando o rol difundido historicamente pela cultura dominante; bem como realizar um mapeamento dos principais folguedos e danças folclóricas praticados no Estado do Rio Grande do Sul que estão situados à margem das práticas dominantes.

Além disso, pretendemos identificar a procedência e/ou influências étnico-culturais predominantes nessas práticas; construir um diagnóstico com as características e situação atuais dessas manifestações populares mediante incursão in loco nos lugares de sua ocorrência; colaborar para a consolidação dos folguedos e danças folclóricas do RS na perspectiva de sua condição enquanto artefatos do patrimônio cultural imaterial; e registrar as produções pesquisadas em meio audiovisual. Pretende-se também produzir conhecimento científico acerca da temática central pesquisada e seus inúmeros atravessamentos possíveis, com vistas à difusão dessa produção por meio de publicações, divulgação on line, realizações e participações em eventos, entre outros, e indicar 
possibilidades de produção artística em dança e música a partir da pesquisa.

Até o presente o momento o projeto transitou por três etapas. A primeira, uma fase mais conceitual e de buscas teóricas, visou englobar todas as discussões em torno dos conceitos de margem, centro, entre-lugar e potência, em paralelo com as investigações sobre o que se entende por cultura gaúcha e cultura sul-rio-grandense. A segunda, o desenvolvimento de um mapeamento das expressões folclóricas encontradas no Estado, resultou no resgate de vinte e duas manifestações populares, a partir de registros principalmente encontrados em Paixão Côrtes ${ }^{4}$ (2006) e Marques (2004). E a terceira, fase que se encontra em andamento, tem enfoque principal nos folguedos do RS, trabalhando na busca de mais registros entre livros, trabalhos acadêmicos, sites e blogs. Ainda nesta etapa, foram escolhidos quatro folguedos, que estão tendo seus estudos mais aprofundados e fundamentados e que possibilitarão dar início à quarta etapa do projeto, que será definida após a finalização da etapa atual.

As manifestações encontradas ora são vistas espontaneamente no seio do povo, ora são temas projetados pela tradição - profana ou religiosa - que chegou até nossos dias através da comunicação popular desenvolvida nas sociedades rio-grandenses. A partir disto, procuramos classificar cada manifestação em folguedo, dança ou festa, sabendo que estas categorias são interligadas e que cada manifestação não acontece de maneira isolada, podendo pertencer a mais de uma categoria. Porém, tal classificação nos permite que a identificação de cada manifestação seja mais precisa.

Para auxiliar o leitor na compreensão do trabalho, considera-se necessário trazer a definição teórica dos acontecimentos folclóricos que são objetos de nossa investigação: os folguedos, as danças e as festas. Segundo explica Côrtes (2000, p. 14-15):

[...] Folguedos indicam as brincadeiras, sortes, jogos, danças e representações dramáticas e coreográficas, exercendo determinada função na sociedade que se interessa por sua criação e manutenção. O caráter interativo e abrangente do folclore permite a mistura de diversos folguedos, observando-se numa mesma festa diferentes manifestações, como músicas, danças, teatros, crendices, superstições, cujos cenários são sempre os locais públicos. 
Ainda sobre folguedos, em A sabedoria popular, Carneiro (2008, p. 17 e 23) nos dá a dimensão de que a "palavra abarca jogos, autos, danças e cortejos folclóricos" e define-os como "manifestações lúdicas da nossa gente" que possuem um "caráter de legítima expressão do povo". Já as danças folclóricas são definidas por Cascia Frade como

[...] expressões populares, desenvolvidas em conjunto ou individualmente, que têm na coreografia o elemento definidor. [...] eram manifestações exclusivamente coletivas, com os dançadores organizados em círculo, fazendo todos, simultaneamente, os mesmos movimentos [...] As danças desenvolvidas em pares, sobretudo os "enlaçados", revelam influência do elemento colonizador. (FRADE, 1997, p. 35-36).

Por fim, as festas, na visão de Côrtes (2000, p. 14-15) conceituam-se como "qualquer solenidade religiosa ou civil" e podem abranger os "cultos e folguedos populares". Elas possuem "particulares situações de tempo e espaço", seguindo algumas datas de comemorações instituídas pelo calendário de festividades católicas, conservando os "costumes de cada região".

No Rio Grande do Sul, assim como em todo o território nacional, os folguedos, as danças e as festas mesclam-se, fazendo com que cada manifestação transite em conjunto com outras manifestações. Assim, pode-se dizer que uma determinada dança pode estar contida nas atividades de um folguedo, que por sua vez pode vir a acontecer em razão de uma festa pertencente a uma determinada comemoração, seja ela religiosa ou profana.

Após pesquisar e identificar as principais características das manifestações populares encontradas no Estado do RS, o projeto elaborou um banco de dados o qual denominou Mapeamento de Manifestações Folclóricas do RS. Tal mapeamento consiste na listagem de manifestações folclóricas, sua classificação em folguedo, dança ou festa, e das informações pesquisadas sobre cada manifestação norteada pelas seguintes perguntas: qual é a manifestação? Como ela acontece? Quando acontece? Quem são seus realizadores? E onde ela acontece? A partir destas perguntas, pode-se dirigir o estudo das vinte e duas manifestações populares encontradas, sendo que até o presente momento contamos com a presença de quinze folguedos, duas danças e cinco festas compondo este mapeamento.

No entanto, neste momento, o trabalho realizado pelo projeto de pesquisa está focado prioritariamente nos folguedos, pois entendemos que estas manifestações corporificam a cultu- 
ra popular do Estado, são mais abrangentes por serem constituídas de várias expressões folclóricas e muitos destes folguedos ainda são realizados atualmente, possibilitando um maior campo de pesquisa. Sendo assim, priorizamos o resgate dos folguedos, porém não excluímos as danças folclóricas e as festas, que serão aprofundadas em outro momento do projeto de pesquisa.

\section{Folguedos no Rio Grande do Sul}

A seguir, listaremos os quinze folguedos constantes no mapeamento, encontrados através de pesquisa teórica realizada principalmente a partir das obras de Paixão Côrtes (2006) e Marques (2004), tendo como pesquisa complementar Cavalari (2011), Hoffmann (2015), Jesus, T. (2013), Lobo (2010) e Jesus, D. e Rodrigues (2013). Os folguedos que figuram em nosso mapeamento inicial são: Baile do Candombe, Batuque, Bumba-meu-boi, Carnaval, Cavalhadas, Congadas, Embaixadas, Ensaio de Promessa de Quicumbi, Folia do Divino, Maçambiques, Masquê, Quicumbis, Ternos de Reis, Terno de Santos e Terno de Atiradores do Ano Novo.

A partir de um primeiro diagnóstico, percebemos que muitas destas manifestações continuam vivas, presentes dentro de suas comunidades, como é o caso do Bumba-meu-boi de Encruzilhada do Sul, as Cavalhadas de Santo Antônio da Patrulha e, ainda, as Congadas e Maçambiques de Osório. Também percebermos que na região litorânea, principalmente nas cidades de Mostardas e Tavares, a presença de diferentes manifestações é marcante, assim como são marcantes os folguedos do Ciclo Natalino, Terno de Reis e Terno de Atiradores do Ano Novo, que permanecem em plena atividade em diversas regiões do Estado. Por outro lado, notamos que manifestações como o Batuque e Baile do Candombe desapareceram.

Após desenvolvermos o mapeamento, organizamos um calendário de manifestações populares do Rio Grande do Sul, o qual utilizamos como instrumento de coleta dos seguintes dados: nome do folguedo, período do ano e cidade(s). Ainda incluímos no calendário informações referentes ao contato das prefeituras das cidades envolvidas, que realizam ou realizaram tais folguedos. $\mathrm{O}$ objetivo do calendário é sistematizar o período do ano e a cidade onde ocorrem os folguedos ainda em atividade, pois a partir destes dados poderemos buscar junto aos órgãos públicos (prefeituras e suas secretarias) mais informações acerca de como acontecem estas manifestações em nosso Estado e ainda quem são as entidades ou grupos que 
as organizam. Também, o calendário nos possibilita a organização de possíveis visitas, para que possamos presenciar os folguedos onde eles acontecem e assim registrá-los, enriquecendo nossa pesquisa.

No momento, a fase do projeto em que nos encontramos é a da escolha de algumas destas manifestações populares do estado do Rio Grande do Sul para o aprofundamento teórico das características já diagnosticadas. Os folguedos selecionados para este ponto da pesquisa são: Bumba-meu-boi, Carnaval, Cavalhadas e Ensaio de Promessa de Quicumbi. A escolha destes folguedos se deu por se tratarem de manifestações que ainda estão vivas no Estado, e que apresentam características bem distintas entre si. Além de buscarmos novos registros sobre estas manifestações, o projeto pretende, ainda no ano de 2017, dar início à pesquisa in loco, para que se consiga uma maior apropriação do tema, seu registro e a caracterização estética e social mais detalhada dos referidos folguedos.

\section{Bumba-meu-Boi}

O folguedo, que também é conhecido no RS por boizinho, possui características de dança teatral e de desfile, que acontece nas ruas da cidade normalmente no período do carnaval. Paixão Côrtes (2006, p. 248) define esta manifestação da seguinte maneira:

[...] o bumba-meu-boi é uma das danças teatrais mais importantes no Brasil. Resultou de vários fatores simultâneos: antigas festas da Igreja no período medieval europeu, a velha "commedia dell'arte" como matriz do teatro popular ocidental, talvez o culto norte-africano ao boi como animal sagrado, etc. O nome "bumba-meu-boi" é mais característico de Pernambuco. Noutros Estados há outras denominações: boi-bumbá no Amazonas, Pará e Maranhão, boi-de-reis no Ceará, boi-calemba no Rio Grande do Norte, reisado em Alagoas, boi-de-mamão em Santa Catarina e boizinho no Rio Grande do Sul.

No Rio Grande do Sul, "as danças teatrais nunca tiveram grande aceitação” (PAIXÃO CÔRTES, 2006, p. 248), pois as danças de salão que incluíam a participação das mulheres faziam parte da preferência popular. Contudo, o boizinho conseguiu se destacar e teve participação significativa em algumas cidades do Rio Grande do Sul; inclusive, ainda hoje podemos apreciar esta manifestação nas localidades que conservam a 
tradição do desfile do boi por suas ruas. Na cidade de Viamão, o folguedo era denominado Boi-tatá, caracterizado pela emissão de luz através dos olhos e boca do animal, a partir de uma lanterna. Em Osório, o boi possuía características semelhantes, sendo chamado de Boi-de-fogo. Ainda com características similares aos bois de Viamão e Osório, também encontramos o Boizinho de Santo Antônio da Patrulha.

Consta ainda que na cidade de Vacaria, o Auto do Boi era realizado no encerramento das comemorações do Dia de Reis, em seis de janeiro. Era uma festa alegórica, na qual havia alguns ensaios e movimentos prescritos que antecediam o momento do boi ir para as ruas. O Bumba-meu-boi era um dos folguedos mais populares da cidade e no seu encerramento havia distribuição de carne aos participantes. A estrutura do boi era feita a partir de sarrafos e varetas, que originavam a sua carcaça, esta era coberta por um pano e em cada uma de suas duas extremidades eram presas a cabeça e a cauda. O responsável por manter presente o folguedo do boi em Vacaria era Bernardo Amaro de Souza, também conhecido como Bernardo Fogueteiro; com a ocasião de sua morte, o boi foi gradualmente perdendo força na cidade.

Segundo consta nas pesquisas realizadas por Paixão Côrtes (2006), a manifestação do Boizinho também foi presenciada em Caxias do Sul, Jaguarão e Passo Fundo. Nestas cidades, diferentemente das anteriores, a herança do folguedo originou-se da cultura afro. $\mathrm{O}$ boizinho também foi popular na região do litoral norte rio-grandense, era mais dramático e possuía personagens; possuía também as figuras do mestre e contramestre. Sendo que o primeiro "puxava a cantoria narrando, descrevendo a sequência dos quadros e em certos momentos, orientava as personagens em cena ou requeria a participação do público", e o contramestre "cantava em $2^{\underline{a}}$ voz, fazia dueto com o Mestre ou respondia o refrão" (PAIXÃO CÔRTES, 2006, p. 248-249).

Hoje possuímos registros do Bumba-meu-boi acontecendo anualmente na cidade de Encruzilhada do Sul. O folguedo ocorre sempre no primeiro sábado após o Carnaval. O grupo responsável pela saída do Boizinho às ruas da cidade outrora foi comandado por Humberto Castro Fossa e Firmino Silveira, já falecidos; desde o ano de 2007 o responsável por manter esta tradição presente nas ruas é Diogo Silveira, neto de Firmino. O folguedo de Encruzilhada é herança dos povos açorianos e acontece aproximadamente há 160 anos e, diferente de outros lugares, somente um boi sai em desfile 
pela cidade. Os participantes do Boizinho rezam momentos antes de sua saída às ruas, e então cumprem um trajeto que vai desde a antiga casa de Seu Firmino (lugar de concentração dos participantes do folguedo) até a praça da cidade, onde a comunidade se encontra para ver o desfile e brincar com o boi.

\section{Carnaval}

Pode-se dizer que o Carnaval do Rio Grande do Sul não figura entre os mais conhecidos e difundidos do país e, em certa medida, está à margem dos principais carnavais de rua de outras regiões do país, tais como os de São Paulo, Rio de Janeiro, Salvador, Olinda/Recife; e muitas pessoas no território brasileiro desconhecem sua existência, sua importância e mesmo suas características. No Estado do RS, festejamos o Carnaval de diversas formas, contando com a presença dos blocos burlescos, das escolas de samba adultas e mirins, das bandas carnavalescas, dos cordões, e muitas outras atrações. A manifestação desenvolve-se mediante ares próprios, variando por região onde é realizada, abarcando, assim, aspectos singulares das culturas locais.

Muitos são os carnavais que se destacam no Rio Grande do Sul. Na cidade de Cruz Alta, até os anos 2000, acontecia o Carnaval D'Água, evento em que os moradores despejavam bacias e "bombas" de água de suas casas sobre os passantes na rua. Hoje, em razão das políticas ambientais, esta prática já não existe mais e a cidade realiza desfiles de escolas de samba e bailes carnavalescos em clubes sociais como atração. Em Santa Bárbara do Sul, até hoje se comemora a data com o tradicional Carnaval do Barro, evento que reúne os habitantes da cidade no "Barródromo" ${ }^{5}$ " para festejar com brincadeiras, música, desfiles de blocos e muita lama.

Ainda no que se refere ao Carnaval, trazemos alguns exemplos: a cidade de Rio Grande se destaca pela presença dos conjuntos acadêmicos e pelo desfile de escolas de samba e desfile dos blocos burlescos na Praia do Cassino. Encruzilhada do Sul (como dito anteriormente), por sua vez, conta com o desfile do Bumba-meu-boi pelas ruas da cidade, realizado no sábado posterior ao feriado de Carnaval. Pelotas é conhecida tradicionalmente pelo seu carnaval de rua, com blocos burlescos, bandas carnavalescas e escolas de samba, além dos bailes em clubes; já a capital Porto Alegre se destaca pelos desfiles das escolas de samba e, mais recentemente, 
pelos blocos burlescos no carnaval de rua. Além destas, Jaguarão, na última década, destaca-se por seus trios elétricos semelhantes aos que animam o Carnaval de Salvador-BA. Em Uruguaiana, o Carnaval é realizado fora da época habitual, desde 2005, tendo como destaque o desfile das escolas de samba, que traz personalidades do carnaval do Rio de Janeiro e São Paulo, além de profissionais de diversas partes do país (como Parintins) e que acontece sempre algumas semanas após a data oficial do calendário.

\section{Cavalhadas}

Este folguedo é descrito como "uma luta simulada na qual os participantes principais - em número de 24 - representam, através de evoluções equestres e movimentos de espada, lança e pistola, uma batalha de fundo religioso entre Mouros e Cristãos" (PAIXÃO CÔRTES, 2006, p. 38). Durante a batalha fictícia, acontece a disputa pela princesa Floripa, a vitória dos cristãos, a tomada do castelo e o batismo dos mouros, que são convertidos ao cristianismo.

As cavalhadas encontraram um ambiente adequado para se desenvolver no RS, principalmente por suas condições mesológicas e também pela própria formação histórica do Estado, repleta de lutas em suas fronteiras e revoluções. De acordo com a pesquisa realizada por Paixão Côrtes (2006), em busca das manifestações folclóricas existentes pelas diferentes regiões, pode-se dizer que as Cavalhadas chegaram ao Estado vindas do centro do país, desde os tempos do Brasil-Colônia.

No Rio Grande do Sul, a representação simbólica da luta que a Cavalhada proporciona nos permite caracterizar 5 aspectos distintos: o dramático, representado pela troca de embaixadas e lutas; o tragicômico, por ocasião da morte do espia; o recreativo durante as provas de diversões; o hilariante através dos pândegos movimentos dos palhaços e social na oportunidade do "baile dos corredores". (PAIXÃO CÔRTES, 2006, p. 43)

A festividade possui a duração de um dia inteiro, principiando normalmente às o8hzomin da manhã, sendo interrompida para o almoço e retornando às $15 \mathrm{~h}$, seguindo por toda a tarde e início da noite. As principais manifestações das cavalhadas são vistas nas cidades de Santo Antônio da Patrulha, Vacaria, Viamão, São Francisco de Paula, Caçapava do 
Sul e Gravataí; geralmente junto às comemorações das Festas do Divino Espírito Santo e outros santos padroeiros, não possuindo uma data fixa definida.

\section{Ensaio de Promessa de Quicumbi}

Este folguedo surge nos quilombos onde os negros escravizados buscavam refúgio dos maus tratos sofridos, sendo assim, está ligado diretamente à condição social de ancestrais explorados, e também à resistência que lhe ressignifica e mantém esta manifestação viva até os dias de hoje. Orlando Mostardas, rei do Congo, relata que o ensaio iniciou-se em 1720, e era realizado em meio a matos (JESUS, D.; RODRIGUES, 2013).

É uma festividade afro-açoriana (JESUS, D.; RODRIGUES, 2013), também considerada afro-brasileira (LOBO, 2010), com sons e memórias da escravidão, transmitidas oralmente. Ela é realizada em comunidades quilombolas rurais, como, Olhos D’Água e Capororocas, nos municípios de Tavares e Mostardas, no Estado do Rio Grande do Sul.

Tal acontecimento inicia a partir de um devoto que, para obter uma graça ou viabilizar o seu alcance, faz uma promessa e paga-a através de cantos, rezas e danças; constituindo, assim, o princípio deste folguedo. No Ensaio de Promessa de Quicumbi, a santa cultuada é Nossa Senhora do Rosário, porém, "não é exclusivo à referida santa, ele pode ser feito a qualquer outro santo da igreja católica, merecendo destaque São Benedito" (JESUS, D.; RODRIGUES, 2013, p. 6). Além disso, ele pode ser realizado no terreiro da casa de quem está pagando a promessa ou dentro da mesma.

O cerimonial de um Ensaio segue, em síntese, os seguintes momentos: o grupo (terno) formado de 8 a 10 pares masculinos, adultos, dirige-se em duas filas à casa onde se desenvolverá o ato de sentido religioso. À frente veem-se os dois guias (conhecidos também por mestre e contramestre) que puxam as cantorias e os movimentos coreográficos, com destaque para um deles, chamado de gerente e a quem cabe o comando geral do auto representativo. Cantam esses líderes em primeira e segunda voz, no que são seguidos em coro, pelos demais, denominados dançantes. (PAIXÃO CÔRTES, 2006, p. 227)

O folguedo, visto como uma manifestação sagrada, possui um altar/oratório para onde o grupo irá se dirigir e onde 
estará localizada uma caixinha azul, que conterá a imagem do Santo homenageado na promessa. A caixinha é parte essencial do Ensaio, pois nela são depositados os agradecimentos e donativos dos promesseiros. À frente do oratório, os dançantes procuram acompanhar os movimentos coreográficos iniciados pelo mestre e contramestre, as coreografias são simples e a movimentação se dá de acordo com os ritmos tocados e andamentos musicais. Antes de encerrar o Ensaio, "é realizada uma figura na qual os dançantes formam diversas rodas de dois pares, em separado, e utilizam-se de lenços, quando cruzam entre si, sempre cantando e dançando" (PAIXÃO CÔRTES, 2006, p. 229). Para encerrar a manifestação, o momento de despedida acontece no mesmo lugar onde o promesseiro iniciou o pagamento de sua promessa. O Ensaio de Promessa de Quicumbi ocorre principalmente na área campesina de Palmares do Sul, Mostardas, Tavares e São José do Norte. Ele pode ser realizado em qualquer data e a qualquer hora, dependendo da promessa que está sendo paga.

\section{Considerações Finais}

Acreditamos que por se tratar de um tema que corporifica a cultura popular do Rio Grande do Sul - tanto com os folguedos, como com as danças folclóricas e as festas mapeadas -, devemos cada vez mais aprofundar tal pesquisa a fim de retratar o maior número de manifestações populares que constituem o Estado como forma de ampliar o acesso e difundir fatos folclóricos que não estão priorizados pelos diferentes veículos de comunicação.

A respeito do Projeto, destacamos ainda que nossas discussões e pesquisas se relacionam também com outras ações parceiras dentro da Universidade Federal de Pelotas, expandindo-se a Projetos de Ensino e Extensão. Estamos em contato direto com o Projeto de Ensino LIFE-LAPIS-Dança, que no momento trabalha no desenvolvimento de material didático sobre danças folclóricas, através da construção de uma cartilha que futuramente será disponibilizada para que a rede escolar utilize-a como mais um recurso que levará o folclore para dentro da escola. E ainda atuamos em parceria com o Núcleo de Folclore da UFpel - NUFOLK e participamos da organização do evento intitulado Semana do Folclore, desenvolvendo ações que possibilitam a disseminação do folclore tanto para o meio acadêmico, quanto para a comunidade em geral através de oficinas, rodas de conversa, web conferências e outros meios. 
É importante destacar que os resultados parciais que estão sendo obtidos podem ser visualizados no blog do projeto www.folcloredemargem.blogspot.com, espaço onde o visitante pode encontrar a descrição de cada folguedo, dança folclórica e festa, bem como imagens e vídeos de algumas destas manifestações populares do Estado, podendo ainda ter acesso às publicações realizadas pelos membros da equipe acerca deste mesmo tema.

\section{NOTAS}

1 Folguedos são manifestações folclóricas que envolvem, além da dança, momentos dramáticos, jogos e brincadeiras. Sua definição será melhor dẹalhada ao longo deste trabalho.

2 Por "cultura gaúcha" entendem-se os usos, costumes e modos comportamentais de determinado grupo que se baseia na figura do gaúcho e no tradicionalismo, sendo difundida amplamente e possuindo predominância sobre outros grupos que também corporificam a cultura do Estado.

3 O Movimento Tradicionalista Gaúcho (MTG) é uma organização sem fins lucrativos que busca a preservação do tradicionalismo, que por sua vez visa valorizar e manter as tradições existentes na cultura gaúcha, que tem como espaços físicos simbólicos da manutenção desta cultura os CTGs - Centro de Tradições Gaúchas.

4 Foi utilizado como referência inicial para o Mapeamento das Manifestações Folclóricas no Rio Grande do Sul, devido ao seu trabalho realizado há mais de 60 anos e editado em um livro na década de 1980, onde trazia uma pesquisa diferenciada sobre folclore gaúcho, distinta do seu trabalho ante ao movimento tradicionalista gaúcho. Devido a este trabalho realizou diversas palestras pelo estado, entre elas $A$ importâncias das manifestações folclóricas no nosso Litoral, em 2005, ocasião na qual foi convidado a reeditar este trabalho.

5 Espaço aberto, localizado na cidade de Santa Bárbara do Sul/RS, onde os foliôes comemoram o Carnaval sujando-se de água, terra e barro.

\section{Referências}

ARISTÓTELES. Metafísica. 2. ed. Lima, Peru: Editorial Universo, 1977.

BHABHA, Homi K. O local da cultura. Belo Horizonte: Editora UFMG, 1998.

CARNEIRO, Edison. A sabedoria popular. 3. ed. São Paulo: Martins Fontes, 2008.

COMISSÃO NACIONAL DE FOLCLORE. [1951] Carta do folclore brasileiro. In: CONGRESSO BRASILEIRO DE FOLCLORE, 8, 12 a 16 de dezembro de 1995, Salvador. Anais... Salvador: [s.e.], 1995. 
CAVALARI, Rossano Viero. Dicionário de Cruz Alta: histórico e ilustrado. Porto Alegre: Martins Livreiro Editor, 2011.

CÔRTES, Gustavo Pereira. Dança, Brasil! Festa e danças populares. Belo Horizonte: Editora Leitura, 2000.

FRADE, Cascia. Folclore. São Paulo: Global, 1997.

GLOBO ED. (Org.). Rio Grande do Sul: Terra e Povo. 2. ed. Porto Alegre: Globo, 1969. 355p.

GOLIN, Tau. A ideologia do gauchismo. Porto Alegre: Tchê, 1983.

HOFFMANN, Carmen Anita. A trajetória do curso de dança da UNICRUZ: 1998 - 2010. 2015. 196 f. Tese (Doutorado em História) - Pontifícia Universidade Católica do Rio Grande do Sul, Porto Alegre, 2015.

JACKS, Nilda. Mídia nativa: indústria cultural e cultura regional. 3. ed. Porto Alegre: Universidade/UFRGS, 2003. 150 p.

JESUS, Daiane de; RODRIGUES, Catrine. Ensaio de pagamento de promessas: histórias e cultura de um povo. In: SILVA, Anelise Ferreira; AMARAL, Danusa Souza (Org.). Coletânea de artigos da Escola Estadual de Ensino Médio Edgar Pereira Velho. Tavares: [s.e.], 2013.

JESUS, Thiago Silva de Amorim. Corpo, ritual, Pelotas e o Carnaval: uma análise dos desfiles de rua entre 2008 e 2013. 2013. $367 \mathrm{f}$. Tese (Doutorado em Ciências da Linguagem) Universidade do Sul de Santa Catarina, Palhoça, 2013.

LOBO, Janaina Campos. Entre gingas e cantigas: etnografia da performance do Ensaio de Promessa de Quibumbi entre os morenos de Tavares, Rio Grande do Sul. 2010. 158 f. Dissertação (Mestrado em Antropologia Social) - Programa de Pós-Graduação em Antropologia Social, Universidade Federal do Rio Grande do Sul, 2010.

MARQUES, Lilian Argentina B. et al. Rio Grande do Sul: aspectos do folclore. Porto Alegre: Martins Livreiro, 2004.

OLIVEN, Ruben George. A parte e o todo: a diversidade cultural no Brasil-nação. Petrópoles: Vozes, 2006.

PAIXÃO CÔRTES, J. C. Folclore gaúcho: festa, bailes, música e religiosidade rural. Porto Alegre: CORAG, 2006.

PRYSTHON, Angela. Margens do mundo: a periferia nas teorias do contemporâneo. Revista FAMECOS, Porto Alegre, v. 1, n. 21, p. 43-50, ago., 2003. 
Recebido em: 30/05/2017 Aprovado em: 06/02/2018 


\section{BELIZA GONZALES ROCHA}

beliza.gr@gmail.com

Licencianda em Dança no Centro de Artes da Universidade Federal de Pelotas/RS. Graduada em Teatro com Habilitação em Direção Teatral pela Universidade Federal do Rio Grande do Sul(UFRGS). Bolsista CNPq do Projeto de Pesquisa Folguedos e Danças Folclóricas Marginais do e no Rio Grande do Sul. Bailarina da Abambaé Companhia de Danças Brasileiras. Tem como área de estudos manifestações populares.

\section{SABRINA MARQUES MANZKE}

bitamarques@gmail.com

Licencianda em Dança, no Centro de Artes da Universidade Federal de Pelotas/RS. Mestre em Antropologia e Especialista em Arte - Patrimônio Cultural pela Universidade Federal de Pelotas(UFPel). Graduada em Comunicação Social pela Universidade Católica de Pelotas (UCPel). Bolsista FAPERGS do Projeto de Pesquisa Folguedos e Danças Folclóricas Marginais do e no Rio Grande do Sul.

\section{THIAGO SILVA DE AMORIM JESUS}

thiagoufpel@gmail.com

Professor Adjunto do Curso de Licenciatura em Dança e Professor do Programa de Pós-Graduação em Artes Visuais no Centro de Artes da UFPel. Doutor em Ciências da Linguagem (UNISUL/SC) e Licenciado em Dança (UNICRUZ/RS). Coordenador do Núcleo de Folclore - NUFOLK e Líder do Grupo de Pesquisa OMEGA - Observatório de Memória, Educação, Gesto e Arte, onde coordena o Projeto Folguedos e Danças Folclóricas Marginais do e no Rio Grande do Sul. Artista Popular da Abambaé Companhia de Danças Brasileiras. 